\title{
COESÃO E RESISTÊNCIA AO CISALHAMENTO RELACIONADAS A ATRIBUTOS FÍSICOS E QUÍMICOS DE UM LATOSSOLO AMARELO DE TABULEIRO COSTEIRO ${ }^{(1)}$
}

\author{
Apolino José Nogueira da Silva ${ }^{(2)} \&$ Fabíola Gomes de Carvalho ${ }^{(3)}$
}

\begin{abstract}
RESUMO
Os solos coesos de tabuleiros costeiros têm como característica peculiar horizontes minerais subsuperficiais, que apresentam consistência friável quando úmidos, porém, quando secos, têm consistência dura, muito dura ou extremamente dura. Este trabalho teve o objetivo de estudar o comportamento mecânico de horizontes coesos e não-coesos de um Latossolo Amarelo de tabuleiro costeiro por meio de características de cisalhamento relacionadas com propriedades físicas, químicas e teor de água do solo. Os resultados mostraram que a coesão do solo e a resistência ao cisalhamento aumentaram expressivamente com a redução do teor de água no horizonte coeso. Este horizonte apresentou os maiores valores de densidade do solo, microporosidade e óxidos de Fe, Si e Al, resultando em maiores valores de coesão do solo e resistência ao cisalhamento, em relação aos horizontes não-coesos. Os maiores valores de coesão do solo resultaram em maiores valores de resistência à penetração no horizonte coeso, em relação aos não-coesos. As características de cisalhamento (coesão do solo, ângulo de atrito interno e resistência ao cisalhamento) mostraram-se sensíveis à identificação de horizontes coesos em solos de tabuleiros costeiros.
\end{abstract}

Termos de indexação: horizonte coeso, resistência à penetração, Formação Barreiras.

\footnotetext{
(1) Recebido para publicação em março de 2006 e aprovado em junho de 2007.

(2) Professor da Escola Agrícola de Jundiaí, Universidade Federal do Rio Grande do Norte - UFRN. Caixa Postal 07, CEP 59280000 Macaíba (RN). E-mail: ajndas@ufrnet.br

(3) Pesquisadora do Departamento de Engenharia Química e Ambiental, Universidade Federal do Rio Grande do Norte - UFRN. BR 101, Campus Universitário, CEP 59072-970 Natal (RN). E-mail: fgcarvalho@eq.ufrn.br
} 


\title{
SUMMARY: COHESIONAND SHEAR STRENGTHAS RELATED TO PHYSICAL AND CHEMICAL PROPERTIES OF A YELLOW LATOSOL OF COASTAL PLAIN
}

\begin{abstract}
The cohesive soils of Brazilian coastal plain have subsurface horizon with a peculiar characteristic - when wet the consistency is friablet, but of hard, very hard or extremely hard consistency when dry. The objective of this study was to evaluate the mechanical characteristics of cohesive and non-cohesive horizons of a Yellow Latosol of coastal tableland based on shear parameters related with soil physical and chemical properties and moisture. The results showed that soil cohesion and shear strength increased substantially with the reduction of the water content in the cohesive horizon. The cohesive horizon presented the highest values of bulk density, microporosity and Fe, Si and Al oxides, resulting in higher values of soil cohesion and shear strength as compared to the non-cohesive horizons. The highest values of soil cohesion resulted in greater resistance to penetration in the cohesive horizon in comparison to the non-cohesive horizons. The shear parameters (soil cohesion, internal friction angle and shear strength) proved sensitive for the identification of cohesive horizons in soils of coastal plains.
\end{abstract}

Index terms: cohesive horizon, penetration resistance, Barreiras formation.

\section{INTRODUÇÃO}

Os solos coesos de tabuleiros costeiros ocupam extensão de mais de $64.000 \mathrm{~km}^{2}$ ao longo da faixa costeira do Brasil; cerca de $82 \%$ desses solos estão situados na região Nordeste do País (Jacomine, 1996). Esses solos são derivados de sedimentos da Formação Barreiras e têm como característica peculiar horizontes minerais subsuperficiais, que apresentam consistência friável quando úmidos; contudo, quando secos, apresentam consistência dura, muito dura ou extremamente dura, exibindo forte coesão (Jacomine, 1996; Ribeiro, 2001b).

Alguns trabalhos estudaram a origem do adensamento nos horizontes subsuperficiais de solos de tabuleiros (Silva, 2000; Ucha, 2000; Ribeiro, 2001a; Filizola et al., 2001) e os efeitos do cultivo e dos sistemas de manejo nas propriedades desses solos (Borges \& Kiehl, 1997; Silva \& Ribeiro, 1998).

Para caracterizar os horizontes coesos dos solos de tabuleiros, têm sido utilizadas propriedades físicas, como densidade do solo, porosidade e resistência à penetração (Giarola et al., 2001; Lima et al., 2004). $\mathrm{O}$ ensaio de cisalhamento direto tem sido pouco usado nos estudos de solos agrícolas no Brasil (Rocha et al., 2002; Silva \& Cabeda, 2005), sendo usualmente empregado em geotecnia, para avaliar a resistência de taludes de terra ao deslizamento (Ortigão, 1995; Pinto, 2000).

As características de cisalhamento do solo são representadas pela coesão do solo, pelo ângulo de atrito interno e pela resistência do solo ao cisalhamento (Ortigão, 1995). A coesão do solo é a força de atração entre as superfícies de suas partículas, podendo ser real ou aparente. A coesão real é resultado do efeito de agentes cimentantes, como teor de óxidos e de argilas silicatadas (Mullins et al., 1990), bem como o resultado da atração entre partículas próximas por forças eletrostáticas (Mitchell, 1976). A coesão aparente é resultado da tensão superficial da água nos capilares do solo, formando meniscos de água entre as partículas dos solos parcialmente saturados, que tendem a aproximá-las entre si. A coesão aparente constitui uma parcela da resistência ao cisalhamento de solos parcialmente saturados (Fredlund \& Rahardjo, 1993).

O ângulo de atrito interno do solo representa as características friccionais entre as partículas do solo, sendo definido como o ângulo máximo que a força transmitida ao solo pode fazer com a força normal à superfície de contato, sem que haja o cisalhamento do solo no plano de ruptura. O ângulo de atrito interno do solo depende de fatores como grau de compactação, percentagem e tipo de argila, tamanho e forma dos grãos de areia do solo (Pinto, 2000).

A resistência do solo ao cisalhamento é determinada pelas características coesivas e friccionais entre as partículas do solo, sendo definida como a tensão máxima cisalhante que o solo pode suportar sem sofrer ruptura (Pinto, 2000). Os principais fatores que influenciam a resistência do solo ao cisalhamento são a distribuição de partículas do solo, a densidade, a estrutura e o teor de água no solo (Mckyes et al., 1994). Em solos de textura arenosa, a resistência ao cisalhamento depende basicamente do atrito entre as partículas, enquanto em solos argilosos ela depende não só do atrito entre partículas, como também da coesão do solo (Lebert \& Horn, 1991).

$\mathrm{Na}$ região Nordeste, poucos trabalhos foram realizados utilizando ensaios de cisalhamento para estudar a coesão de solos na agricultura. Silva \& Cabeda (2005) estudaram os efeitos de diferentes sistemas de manejo com cana-de-açúcar nas características de 
cisalhamento de um Argissolo Amarelo de tabuleiro, verificando aumento na coesão do solo, no ângulo de atrito interno e resistência ao cisalhamento dos solos cultivados, em relação ao solo sob mata nativa.

A influência dos óxidos de $\mathrm{Fe}$, $\mathrm{Si}$ e $\mathrm{Al}$ como agentes cimentantes nas camadas subsuperficiais dos solos coesos de tabuleiros tem sido verificada por alguns autores, dentre os quais Boulet et al. (1998), Silva (2000) e Ribeiro (2001a). A determinação da coesão do solo e resistência ao cisalhamento, bem como sua correlação com atributos como óxidos de $\mathrm{Fe}$, $\mathrm{Si}$ e Al, teor de argila e densidade do solo, pode contribuir para caracterização dos horizontes coesos dos solos de tabuleiros.

Objetivou-se com este trabalho avaliar o comportamento mecânico de horizontes não-coesos (A e Bw2) e coeso (BA) de um Latossolo Amarelo de tabuleiro costeiro, por meio de determinações da coesão, resistência ao cisalhamento e ângulo de atrito interno do solo, e correlacioná-los com atributos físicos, químicos e teor de água do solo.

\section{MATERIAL E MÉTODOS}

O trabalho foi desenvolvido com amostras de um Latossolo Amarelo coeso típico (Embrapa, 1999), localizado no município de São Miguel dos Campos (AL), sob floresta subperenifólia. O solo é derivado do Grupo Barreiras, que se caracteriza por sedimentos areno-argilosos, constituídos principalmente por quartzo na fração areia e caulinita na fração argila, com baixos teores de óxidos de Fe (Jacomine et al., 1975). A área tem clima tropical chuvoso com verão seco (As', segundo a classificação de Köppen). A precipitação pluvial média anual fica em torno de $1.200 \mathrm{~mm}$ e a temperatura média anual, em torno de $29^{\circ} \mathrm{C}$, com relevo predominantemente plano a suave ondulado, característico da região de Tabuleiros Costeiros (Jacomine et al., 1975).

Para estudar o comportamento coeso e não-coeso dos horizontes do Latossolo Amarelo, foram determinadas as características de cisalhamento do solo (coesão, ângulo de atrito interno e resistência ao cisalhamento) e estudada a relação dessas características com as físicas (densidade do solo, porosidade, granulometria, argila dispersa, argila fina e resistência à penetração) e químicas (óxidos de $\mathrm{Fe}$, $\mathrm{Si}$ e Al livres) e o teor de água do solo. As amostras foram coletadas dos horizontes $\mathrm{A}$ (não-coeso), $\mathrm{BA}$ (coeso) e Bw2 (não-coeso) (Quadro 1). Com relação à morfologia, o horizonte A (não-coeso) apresenta estrutura granular e consistência ligeiramente dura quando seca e muito friável quando úmida. O horizonte BA (coeso) tem estrutura maciça e consistência muito dura quando seca e friável quando úmida, e o horizonte Bw2 (não-coeso) apresenta estrutura em blocos subangulares, com consistência ligeiramente dura quando seca e friável quando úmida.

A densidade do solo foi determinada com amostras indeformadas coletadas com anel volumétrico, com quatro repetições, e a densidade das partículas foi

Quadro 1. Características físicas e químicas dos horizontes A, BA e Bw2 de um Latossolo Amarelo de São Miguel dos Campos, AL

Horizonte

$\overline{A(\text { não-coeso }) \quad \text { BA (coeso) } \quad \text { Bw2 (não-coeso) }}$

\begin{tabular}{|c|c|c|c|}
\hline Profundidade (m) & $0,0-0,16$ & $0,32-0,67$ & $1,37-2,02$ \\
\hline $\mathrm{LC}\left(\mathrm{kg} \mathrm{kg}^{-1}\right)$ & 0,13 & 0,14 & 0,14 \\
\hline $\mathrm{LP}\left(\mathrm{kg} \mathrm{kg}^{-1}\right)$ & 0,21 & 0,22 & 0,23 \\
\hline Areia grossa $\left(\mathrm{g} \mathrm{kg}^{-1}\right)$ & 211 & 121 & 103 \\
\hline Areia média $\left(\mathrm{g} \mathrm{kg}^{-1}\right)$ & 269 & 235 & 203 \\
\hline Areia fina $\left(\mathrm{g} \mathrm{kg}^{-1}\right)$ & 140 & 188 & 151 \\
\hline Silte $\left(\mathrm{g} \mathrm{kg}^{-1}\right)$ & 85 & 95 & 91 \\
\hline Argila $\left(\mathrm{g} \mathrm{kg}^{-1}\right)$ & 295 & 361 & 452 \\
\hline Classe textural & Franco argilo-arenosa & Argilo-arenosa & Argilo-arenosa \\
\hline $\operatorname{COT}\left(\mathrm{g} \mathrm{kg}^{-1}\right)$ & 23,9 & 5,1 & 4,6 \\
\hline $\mathrm{CTC}\left(\mathrm{cmol}_{\mathrm{c}} \mathrm{kg}^{-1}\right)$ & 12,1 & 5,8 & 5,2 \\
\hline $\mathrm{pH} \quad \mathrm{H}_{2} \mathrm{O}(1: 2,5)$ & 4,3 & 4,1 & 4,3 \\
\hline
\end{tabular}

LC: limite de contração; LP: limite de plasticidade; COT: carbono orgânico; CTC: capacidade de troca de cátions efetiva; areia grossa $(2-0,5 \mathrm{~mm})$; areia média $(0,5-0,25 \mathrm{~mm})$; areia fina $(0,25-0,05 \mathrm{~mm})$. 
determinada por meio do balão volumétrico, utilizando álcool etílico. A porosidade total foi calculada a partir dos valores da densidade do solo e densidade de partículas (Embrapa, 1997). Os microporos $(\phi<50 \mu \mathrm{m})$ foram obtidos a partir da umidade volumétrica na tensão de $-6 \mathrm{kPa}$, e os macroporos $(\phi \geq 50 \mu \mathrm{m})$, pela diferença entre os valores da porosidade total e dos microporos (Embrapa, 1997). Os limites de contração e plasticidade do solo foram obtidos conforme Embrapa (1997).

A granulometria foi determinada pelo método da pipeta, em quatro repetições, usando-se solução de hexametafosfato de sódio como agente dispersante, $\mathrm{e}$ a argila dispersa em água, usando-se o mesmo procedimento para determinação da argila total, porém sem emprego do dispersante químico (Embrapa, 1997). A argila fina foi determinada por centrifugação, conforme Jackson (1965).

Para ensaio de cisalhamento direto foram retiradas amostras indeformadas, em quatro repetições, com auxílio de amostrador com anéis metálicos rígidos de $6,5 \mathrm{~cm}$ de diâmetro e $2,5 \mathrm{~cm}$ de altura, nos horizontes A (não-coeso), BA (coeso) e Bw2 (não-coeso). As amostras foram acondicionadas com filmes de PVC e espuma, para serem transportadas sem perturbação até o laboratório. O ensaio de cisalhamento foi realizado em equipamento de cisalhamento direto, sendo a amostra colocada em caixa bipartida, na qual foram aplicadas as tensões normal e cisalhante, com velocidade de deslocamento de $0,3 \mathrm{~mm} \mathrm{~min}^{-1}$, até ocorrer a ruptura da amostra ao longo de um plano horizontal. Os ensaios de cisalhamento direto foram realizados em amostras de solo com teores médios de água de $0,07,0,12,0,19$ e $0,24 \mathrm{~kg} \mathrm{~kg}^{-1}$, sendo os parâmetros intercepto de coesão e ângulo de atrito interno determinados conforme Lambe (1951), ajustando-se à equação de Coulomb (equação 1) os valores de tensão de cisalhamento obtidos com a aplicação de tensões normais de 34,7; 138,7; 277,4 e $554,9 \mathrm{kPa}$.

$$
\tau=c+\sigma_{n} \tan \phi
$$

em que $\tau=$ tensão cisalhante $(\mathrm{kPa}) ; \mathrm{c}=$ intercepto de coesão do solo $(\mathrm{kPa}) ; \sigma_{n}=$ tensão normal aplicada $(\mathrm{kPa})$ e $\phi=$ ângulo de atrito interno do solo $\left(^{\circ}\right)$.

Os óxidos $\mathrm{Fe}_{2} \mathrm{O}_{3}, \mathrm{SiO}_{2}$ e $\mathrm{Al}_{2} \mathrm{O}_{3}$ foram extraídos com citrato-ditionito-bicarbonato de sódio (Fed, Sid e Ald, respectivamente) e determinados por espectrofotometria de absorção atômica, conforme Mehra \& Jackson (1960).

A resistência do solo à penetração foi determinada com auxílio de penetrômetro estático em amostras indeformadas, com teores médios de água de $0,07,0,12$, 0,19 e $0,24 \mathrm{~kg} \mathrm{~kg}^{-1}$. Para obtenção desses teores, as amostras foram saturadas com água e submetidas a potenciais mátricos baseados em curva característica de água do solo obtida previamente.

Para observações micromorfológicas foram coletadas amostras indeformadas dos horizontes A,
BA e Bw2, com auxílio de caixas de Kubiena. As amostras foram coletadas na região central (metade da espessura) dos horizontes, sendo devidamente etiquetadas, com identificação e orientação. A confecção das lâminas delgadas foi feita de acordo com Jongerius \& Heintzberger (1963), com impregnação da amostra com resina poliéster, sendo posteriormente submetida a polimentos sucessivos em sistema rotativo automático. As seções delgadas foram estudadas com microscópio petrográfico de luz transmitida, para observações da organização da matriz do solo. As fotomicrografias foram obtidas com câmara fotográfica acoplada ao microscópio, utilizando filmes coloridos ISO 400.

Os dados foram submetidos à análise de variância e a comparação das médias, realizada pelo teste de Tukey a $5 \%$, usando-se o software ASSISTAT (Silva, 1996). As significâncias das equações de regressão foram testadas pelo teste $\mathrm{F}$, e as equações, estimadas usando-se o software SigmaStat 2.03 (SPSS, 1995). Os dados de coesão e teores dos óxidos do solo foram submetidos à análise de correlação de Pearson, utilizando-se o software SigmaStat 2.03.

\section{RESULTADOS E DISCUSSÃO}

A coesão do solo foi influenciada pelo teor de água nos três horizontes estudados (Figura 1). No horizonte A (não-coeso) verificou-se aumento de 20,5 para $60,3 \mathrm{kPa}$ nos valores médios de coesão do solo quando o teor de água reduziu de 0,24 para $0,07 \mathrm{~kg} \mathrm{~kg}^{-1}$, respectivamente (Figura 1). No horizonte BA (coeso), no entanto, a coesão do solo aumentou expressivamente com a redução do teor de água de 0,24 para $0,07 \mathrm{~kg} \mathrm{~kg}^{-1}$, passando de 34,8 para $226,7 \mathrm{kPa}$, respectivamente. No horizonte $\mathrm{Bw} 2$ (não-coeso), a redução do teor de água resultou em aumento da coesão do solo até atingir um valor médio de $101,6 \mathrm{kPa}$, no teor de água de $0,07 \mathrm{~kg} \mathrm{~kg}^{-1}$.

A comparação das médias de coesão do solo indicou que, nos teores de água mais altos $\left(0,19\right.$ e $\left.0,24 \mathrm{~kg} \mathrm{~kg}^{-1}\right)$, não houve diferença significativa na coesão dos três horizontes estudados. O teor de água de $0,19 \mathrm{~kg} \mathrm{~kg}^{-1}$ está entre os limites de plasticidade e contração (Quadro 1), ou seja, dentro da faixa de friabilidade (Hillel, 1980), e o teor de água de $0,24 \mathrm{~kg} \mathrm{~kg}^{-1}$ está acima do limite de plasticidade, com o solo no estado de consistência plástica. Nos teores de água de 0,07 e $0,12 \mathrm{~kg} \mathrm{~kg}^{-1}$, que estão abaixo do limite de contração (Quadro 1), com o solo exibindo consistência dura (Hillel, 1980), a coesão do horizonte BA (coeso) foi significativamente maior em relação à dos horizontes A e Bw2 (não-coesos).

Os maiores valores de coesão do solo no horizonte BA (coeso), quando o teor de água do solo está baixo, refletem as características físicas desse horizonte, que apresentou maiores valores de densidade do solo e microporosidade e menor porosidade total (Quadro 2), 


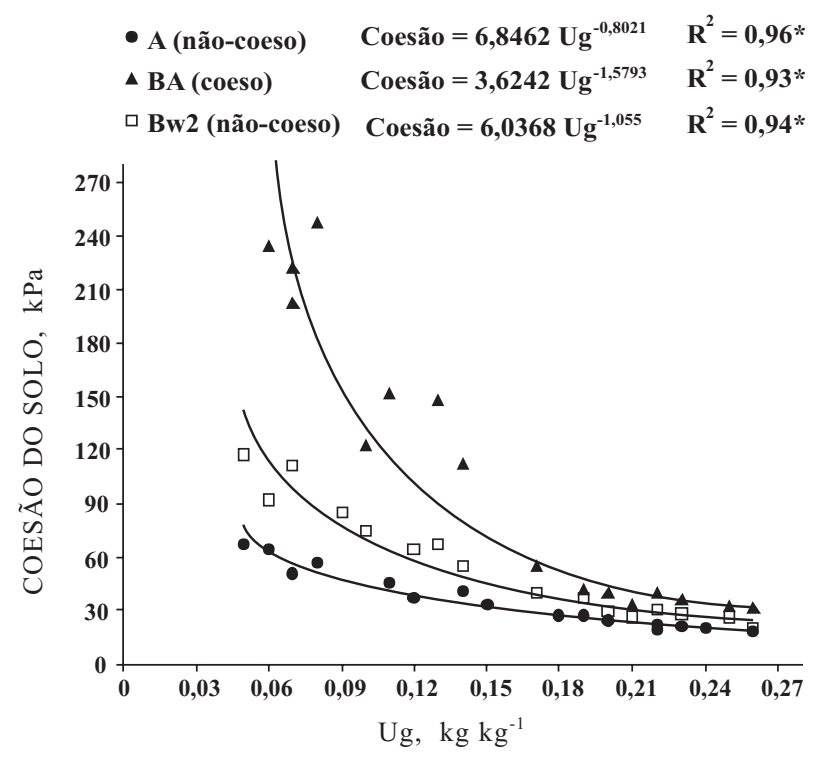

Figura 1. Coesão do solo (kPa) como variável do teor de água (Ug) nos horizontes A (não-coeso), BA (coeso) e Bw2 (não-coeso) de um Latossolo Amarelo de São Miguel dos Campos, AL.

em relação aos horizontes A e Bw2 (não-coesos). Essas características físicas indicam maior adensamento do horizonte BA, refletindo em maior coesão do solo. A figura 2 mostra a correlação positiva e significativa entre a coesão e a densidade do solo. De acordo com Lambe \& Whitman (1979), a maior densidade do solo promove a proximidade entre suas partículas, favorecendo o desenvolvimento da coesão quando o solo está com baixo teor de água.

O maior teor de argila dispersa em água no horizonte BA (coeso), em relação aos horizontes nãocoesos (Quadro 2), também contribui para maior adensamento desse horizonte, pelo preenchimento de poros com argila iluvial, como observado por Silva (2003) em um Argissolo Amarelo de Alagoas. O horizonte BA apresenta o maior teor de areia fina
(Quadro 1), que possibilita um arranjamento em que grãos menores se ajustam entre os maiores, resultando em maior adensamento deste horizonte, em relação aos não-coesos. Abraão et al. (1988) constataram maior compacidade relativa em horizontes subsuperficiais com maior teor de areia fina e maior desuniformidade na granulometria das partículas de areia.

Apesar de os horizontes BA (coeso) e Bw2 (não-coeso) estarem na mesma classe textural (Quadro 1), o maior teor de argila fina no BA (Quadro 2) possivelmente contribuiu para maior coesão neste horizonte, em relação ao Bw2. A fração argila fina possui alta área superficial específica, aumentando a coesão do solo devido à atração entre as partículas por forças eletrostáticas quando o solo está com baixa umidade (Fredlund \& Rahardjo, 1993). A mineralogia caulinítica predominante na fração argila dos solos de tabuleiros (Jacomine, 1996) possivelmente tem influência no desenvolvimento da coesão do solo. Segundo Ferreira et al. (1999), o ajuste face a face das placas da caulinita favorece o desenvolvimento de estrutura em blocos, podendo aumentar a coesão do solo em relação a solos oxídicos, que apresentam predomínio de estrutura granular.

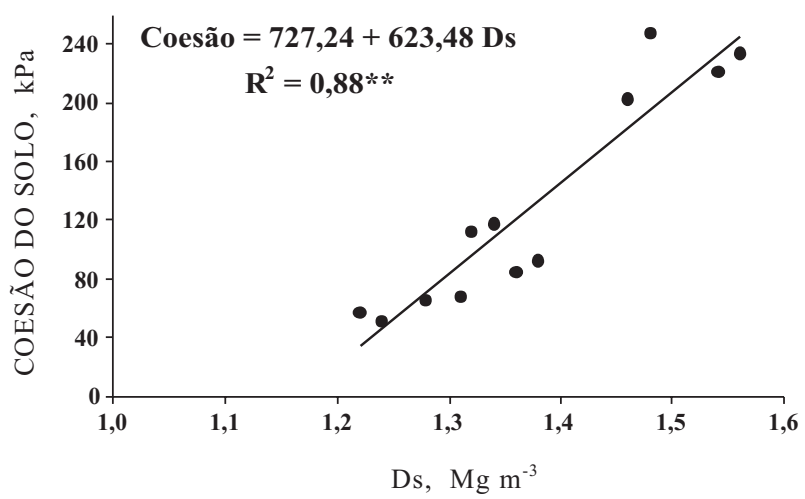

Figura 2. Coesão como variável da densidade (Ds) de um Latossolo Amarelo de São Miguel dos Campos, AL, no teor de água de $0,07 \mathrm{~kg} \mathrm{~kg}^{-1}$.

Quadro 2. Argila dispersa em água (ADA), argila fina (AF), densidade do solo (Ds), porosidade total, macroporos e microporos nos horizontes A, BA e Bw2 de um Latossolo Amarelo de São Miguel dos Campos, AL

\begin{tabular}{lrrrrrr}
\hline Horizonte & ADA & AF & Ds & Porosidade total & Macroporos & Microporos \\
\hline & & & & & & \\
\hline
\end{tabular}

Letras minúsculas iguais na mesma coluna não diferem estatisticamente pelo teste Tukey a $5 \%$ Macroporos ( $\phi \geq 50$ mm), microporos $(\phi<50 \mathrm{~mm})$. 
Os teores de óxidos de Fe, Si e Al extraídos com ditionito-citrato-bicarbonato de sódio (Fed, Sid e Ald, respectivamente) aumentaram em profundidade, sobretudo do horizonte A para o BA (Figura 3a), devido ao incremento no teor de argila em profundidade (Quadro 1). As relações Fed/Argila, Ald/Argila e Sid/ Argila, no entanto, foram maiores no horizonte BA (coeso) em relação aos horizontes A e Bw2 (Figura 3b), evidenciando acúmulo desses óxidos no BA, o que provavelmente contribui para a maior coesão neste horizonte. A influência dos óxidos como agentes cimentantes no desenvolvimento da coesão do solo tem sido enfatizada na literatura (Mckeague \& Sprout, 1975; Franzmeier et al., 1996). Lima et al. (2004) encontraram incremento de óxidos de Si no horizonte coeso de um Argissolo Amarelo de tabuleiro, que apresentou maior resistência do solo à penetração, em relação ao horizonte não-coeso. Estes autores, no entanto, não observaram incremento de óxidos de $\mathrm{Fe}$ e $\mathrm{Al}$ no horizonte coeso, em relação aos não-coesos.

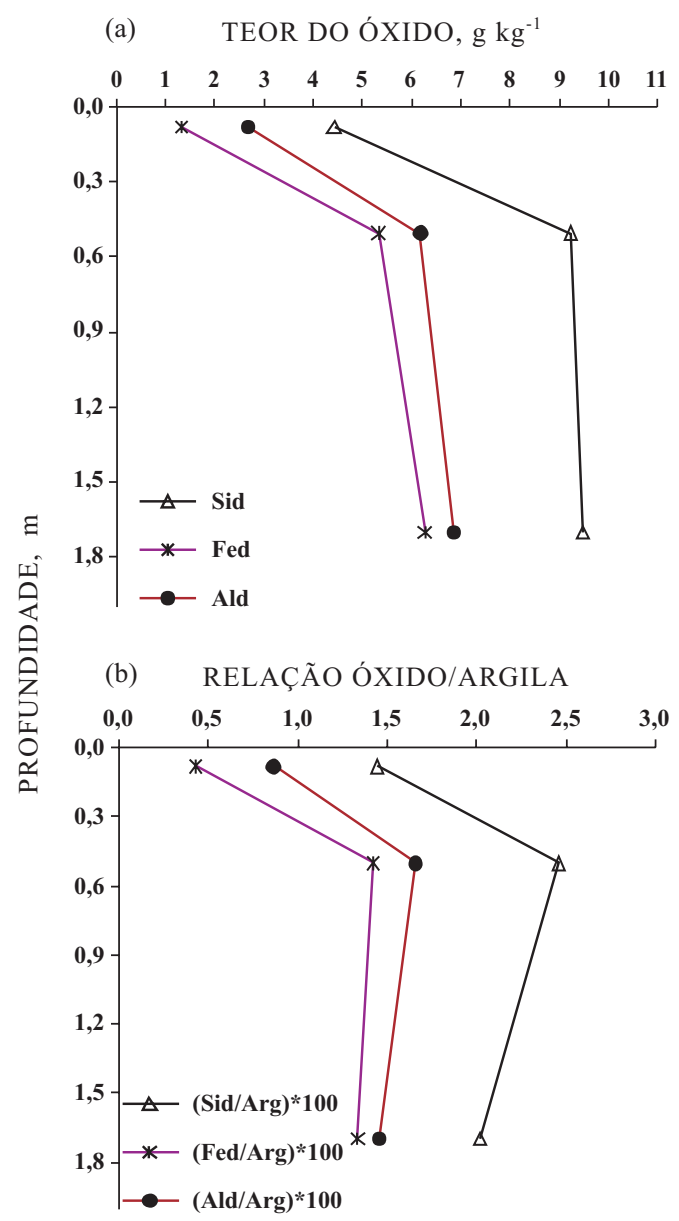

Figura 3. Óxidos de ferro (Fed), silício (Sid) e alumínio (Ald) extraídos por ditionito-citratobicarbonato (a) e relações óxidos/argila (b) nos horizontes A (0,0-0,16 m), BA (0,32-0,67 m) e Bw2 (1,37-2,02 m) de um Latossolo Amarelo de São Miguel dos Campos, AL.
No presente estudo, a coesão do solo correlacionouse significativamente com os óxidos livres Sid $\left(r=0,63^{*}\right)$, Fed $\left(r=0,56^{*}\right)$ e Ald $\left(r=0,58^{*}\right)$ no teor de água de $0,07 \mathrm{~kg} \mathrm{~kg}^{-1}$, sugerindo a influência de tais compostos na coesão do solo. Chartres et al. (1990) constataram redução significativa da coesão do solo e resistência ao cisalhamento após remoção de óxidos de Fe dos horizontes adensados de solos da Austrália (Hardsetting soils), enfatizando a influência desses óxidos como agentes cimentantes.

Observações realizadas com microscópio petrográfico em lâminas delgadas mostraram no horizonte $\mathrm{A}$ (não-coeso) uma estrutura predominantemente granular, com frouxidão no empacotamento da fração grosseira (areia) e dos agregados, que estão visivelmente rodeados por macroporos (Figura 4a). A fração fina possui coloração bruno-escura no horizonte A, indicando típica associação com a matéria orgânica, observando-se fragmentos de plantas em diversos estádios de decomposição (Figura 4a).

No horizonte BA (coeso), no entanto, observa-se um fundo matricial com a fração grosseira embebida no plasma, com porosidade visivelmente reduzida (Figura 4b), caracterizando maior adensamento desse horizonte, como constatado pelos maiores valores de densidade e microporosidade (Quadro 2), o que refletiu em maior coesão do solo (Figura 1). A maior coesão do solo no horizonte BA (coeso) leva à dificuldade de penetração das raízes das plantas, que usualmente tendem a desviar o seu crescimento da linha vertical (Figura 4c), procurando evitar o horizonte coeso. O horizonte Bw2 apresentou predomínio de estrutura em blocos subangulares (Figura 4d), exibindo fundo matricial com aspecto menos adensado em relação ao do horizonte BA, o que foi constatado pela maior porosidade e menor densidade do solo (Quadro 2), comparando ao horizonte BA (coeso).

Verifica-se redução do ângulo de atrito interno do solo com o aumento do teor de água nos horizontes estudados (Quadro 3). De acordo com Lambe \& Whitman (1979), à medida que o teor de água do solo aumenta, a água age como lubrificante entre as partículas do solo, diminuindo o atrito entre elas. Houve redução do ângulo de atrito interno com a profundidade (Quadro 3), devido aos maiores teores de argila nos horizontes subsuperficiais (Quadro 1). Segundo Al-Shayea (2001), quanto maior o teor de argila, menor o ângulo de atrito interno do solo, pois as partículas de argila revestem a superfície das partículas de areia, diminuindo o atrito interno do solo. No presente estudo, o ângulo de atrito interno correlacionou-se negativamente com o teor de argila do solo $\left(r=-0,87^{* *}\right)$, evidenciando o efeito da fração argila na redução do atrito entre partículas.

A resistência ao cisalhamento $(\tau)$ aumentou com a redução da umidade nos três horizontes estudados (Figura 5), concordando com os resultados obtidos por Ayers (1987) e Silva et al. (2004). A maior resistência do solo ao cisalhamento quando o teor de água é baixo 
(a)

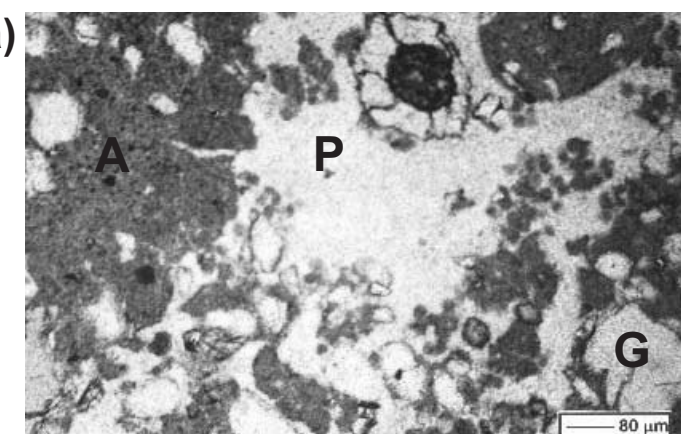

(c)

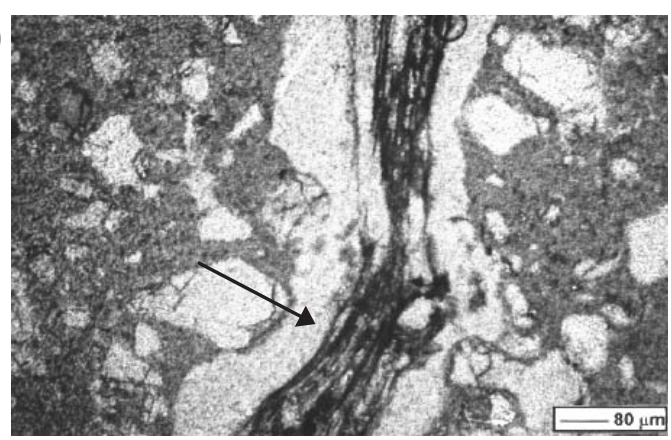

(b)

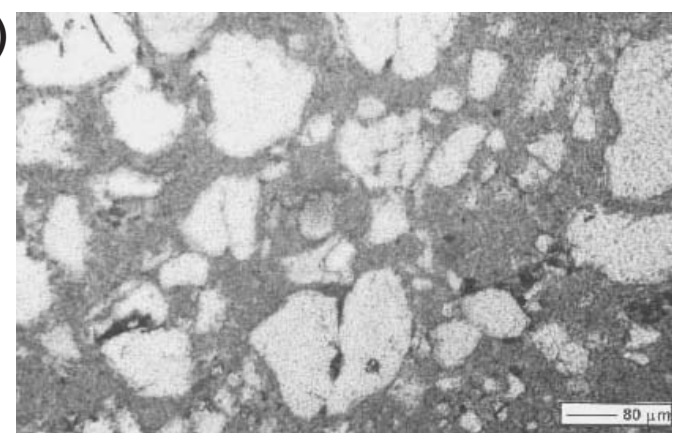

(d)

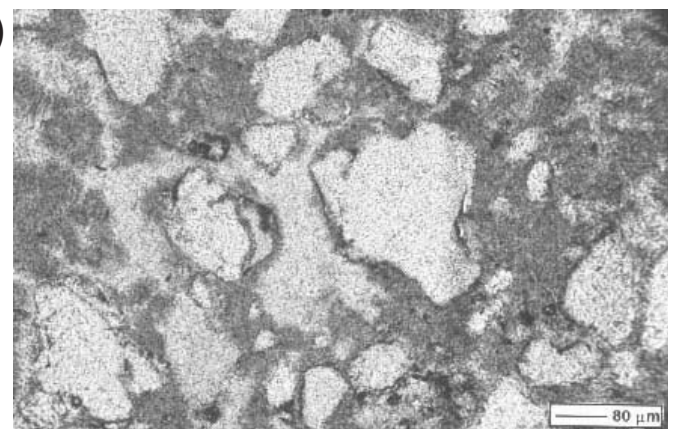

Figura 4. Micrografias obtidas por microscópio petrográfico em amostras de um Latossolo Amarelo: (a) horizonte A (não-coeso), mostrando estrutura granular, com agregados rodeados por macroporos; (b) horizonte BA (coeso) com aspecto maciço na matriz do solo, com predomínio de microporos; (c) penetração de raiz (seta) no topo do horizonte BA (coeso); (d) horizonte Bw2 (não-coeso), mostrando estrutura em blocos subangulares, com aspecto menos adensado que o horizonte $\mathrm{BA}$. $\mathrm{P}=$ poro; $\mathrm{A}=$ agregado; $\mathrm{G}=$ grão de areia.

Quadro 3. Ângulo de atrito interno do solo $\left(\phi,^{\circ}\right)$ como variável dos teores de água (Ug) nos horizontes A, BA e Bw2 de um Latossolo Amarelo de São Miguel dos Campos, AL

\begin{tabular}{|c|c|c|c|c|}
\hline \multirow{2}{*}{ Horizonte } & \multicolumn{4}{|c|}{ Teor de água (Ug, $\left.\mathrm{kg} \mathrm{kg}^{-1}\right)$} \\
\hline & 0,07 & 0,12 & 0,19 & 0,24 \\
\hline A (não-coeso) & $42,3 \mathrm{Aa}$ & $40,0 \mathrm{Aa}$ & $36,1 \mathrm{Ba}$ & $35,8 \mathrm{Ba}$ \\
\hline BA (coeso) & $37,2 \mathrm{Ab}$ & $36,5 \mathrm{ABb}$ & $34,6 \mathrm{BCab}$ & $34,2 \mathrm{Ca}$ \\
\hline Bw2 (não-coeso) & $34,6 \mathrm{Ac}$ & $33,4 \mathrm{ABc}$ & $33,0 \mathrm{ABb}$ & $31,4 \mathrm{Bb}$ \\
\hline
\end{tabular}

Médias com letras maiúsculas iguais, na mesma linha, e letras minúsculas iguais, na mesma coluna, não diferem estatisticamente entre si pelo teste de Tukey a $5 \%$.

reflete a influência das características coesivas e friccionais do solo, como verificado pelos maiores valores da coesão do solo (Figura 1) e do ângulo de atrito interno do solo (Quadro 3).

No horizonte A, que possui menor teor de argila, a resistência do solo ao cisalhamento aumentou expressivamente a partir da tensão vertical de $277 \mathrm{kPa}$ (Figura 5a), em que a redução da porosidade promoveu maior contato entre as partículas, refletindo em maior incremento do ângulo de atrito interno com a redução do teor de água no solo. Nos horizontes BA (Figura 5b) e Bw2 (Figura 5c), a resistência do solo ao cisalhamento aumentou a partir da tensão vertical de $34 \mathrm{kPa}$, devido aos seus maiores teores de argila (Quadro 1), que promovem forte incremento da coesão do solo com a redução do teor de água.

Considerando o teor de água de $0,19 \mathrm{~kg} \mathrm{~kg}^{-1}$, que está entre os limites de contração e plasticidade (faixa de friabilidade) (Quadro 1), verifica-se pouca diferença entre os valores de resistência ao cisalhamento nos 


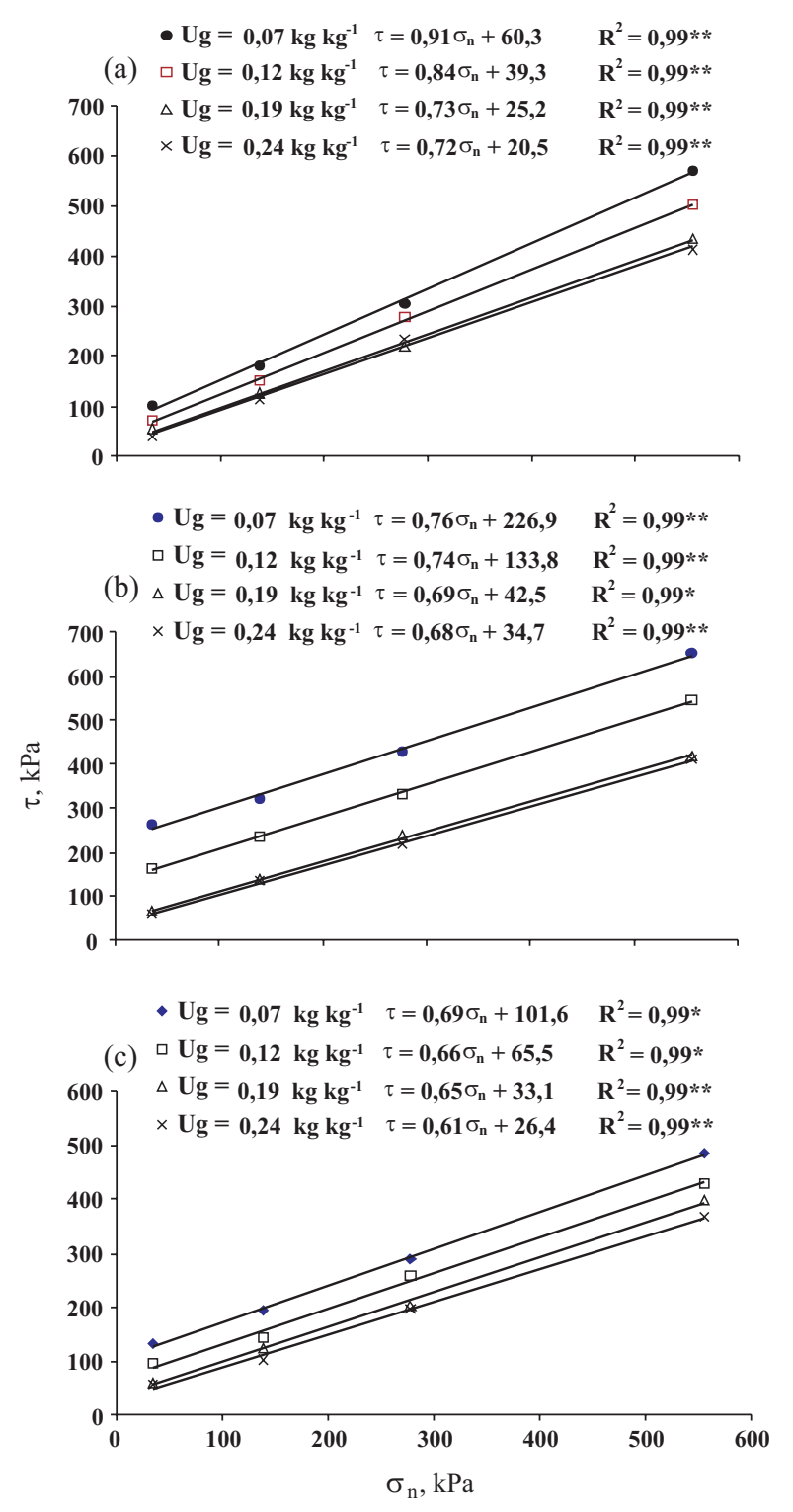

Figura 5. Tensão cisalhante $(\tau)$ como variável da tensão normal $\left(\sigma_{n}\right)$ sob diferentes teores de água. (a) horizonte A (não-coeso); (b) horizonte BA (coeso); c) horizonte Bw2 (não-coeso).

três horizontes estudados (Figura 6a), o que reflete a pouca diferença nos valores de coesão do solo e do atrito interno entre os horizontes nesse teor de água do solo.

No teor de água de $0,07 \mathrm{~kg} \mathrm{~kg}^{-1}$, que está abaixo do limite de contração do solo, verifica-se maior resistência ao cisalhamento no horizonte BA (coeso), em relação aos horizontes $\mathrm{A}$ e Bw2 (não-coesos) (Figura 6b). A maior resistência ao cisalhamento do horizonte $\mathrm{BA}$, em relação ao $\mathrm{A}$, na umidade de $0,07 \mathrm{~kg} \mathrm{~kg}^{-1}$, reflete os maiores valores de coesão do solo (Figura 1), o que evidencia o efeito predominante das características coesivas, já que o ângulo de atrito interno no horizonte BA é menor que no A (Quadro 3). A maior resistência ao cisalhamento do horizonte BA,

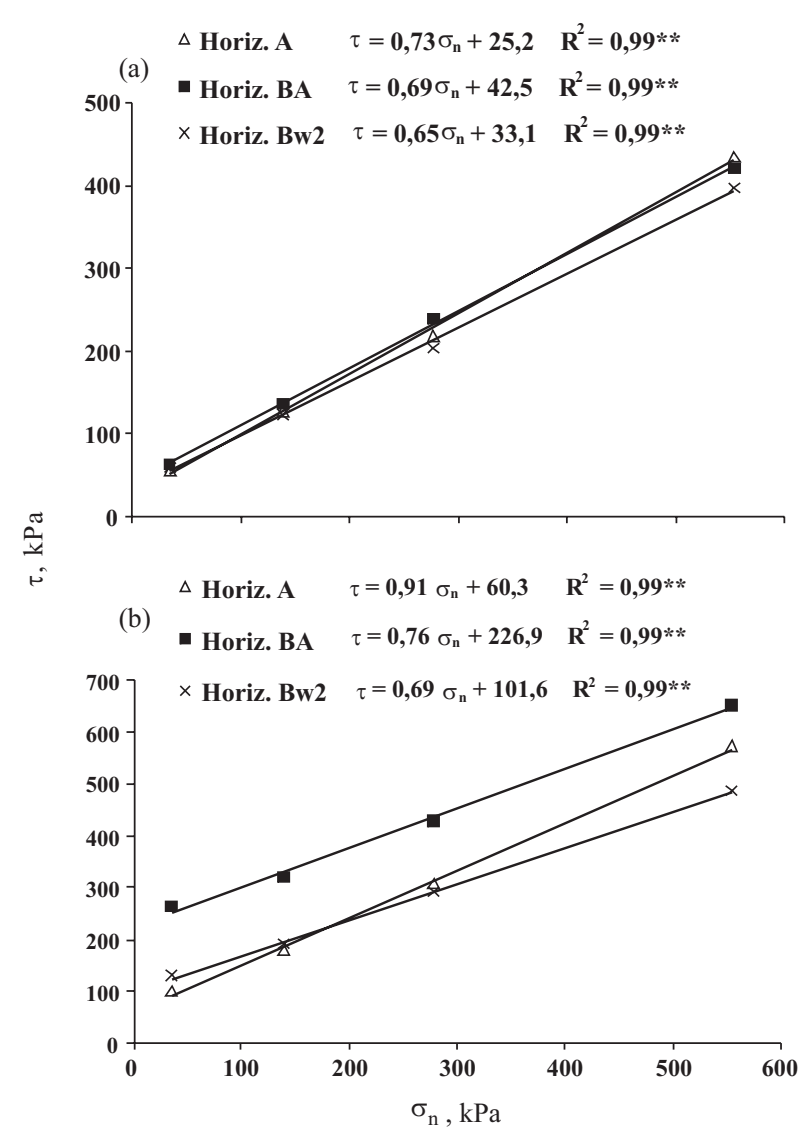

Figura 6. Tensão cisalhante $(\tau)$ como variável da tensão normal $\left(\sigma_{n}\right)$ de amostras dos horizontes coeso (BA) e não-coesos (A e Bw2) de um Latossolo Amarelo de São Miguel dos Campos, AL, nos teores de água de 0,19 (a) e $0,07 \mathrm{~kg} \mathrm{~kg}^{-1}$ (b).

em relação ao Bw2, reflete o efeito das características coesivas e friccionais, como verificado pelos maiores valores de coesão do solo (Figura 1) e do ângulo de atrito interno do solo (Quadro 3) no horizonte BA (coeso). Os maiores valores da resistência ao cisalhamento no horizonte BA também refletem os maiores valores de densidade do solo, em relação aos horizontes nãocoesos (Quadro 2), corroborando os resultados encontrados por Zhang et al. (2001) e Rocha et al. (2002), os quais verificaram aumento da resistência ao cisalhamento em solos com maior densidade.

Os maiores valores de coesão do solo (Figura 1) no horizonte BA (coeso) refletiram em maior resistência do solo à penetração neste horizonte (Quadro 4), em relação aos horizontes A e Bw2 (não-coesos), nos teores de água mais baixos. A influência da coesão do solo na resistência à penetração é evidenciada pela correlação positiva e significativa entre esses dois atributos do solo (Figura 7).

No horizonte BA (coeso), a resistência à penetração chegou aos valores de 3,82 e 6,76 MPa nos teores de água de 0,12 e $0,07 \mathrm{~kg} \mathrm{~kg}^{-1}$, respectivamente. Giarola et al. (2001) também encontraram valores elevados 
Quadro 4. Resistência do solo à penetração $(\mathrm{RP})$ como variável dos teores de água (Ug) nos horizontes $\mathrm{A}$, $\mathrm{BA}$ e Bw2 de um Latossolo Amarelo de São Miguel dos Campos, AL

\begin{tabular}{lcccc}
\hline \multirow{2}{*}{ Horizonte } & \multicolumn{4}{c}{ Teor de água $\left(\mathbf{U g}, \mathbf{k g ~ k g}^{-1}\right)$} \\
\cline { 2 - 4 } & $\mathbf{0 , 0 7}$ & $\mathbf{0 , 1 2}$ & $\mathbf{0 , 1 9}$ & $\mathbf{0 , 2 4}$ \\
\cline { 2 - 4 } & & & $\mathbf{M P a}$ & $0,57 \mathrm{Ca}$ \\
A (não-coeso) & $1,99 \mathrm{Ac}$ & $1,03 \mathrm{Bc}$ & $0,76 \mathrm{BCb}$ & $0,67 \mathrm{Da}$ \\
BA (Coeso) & $6,76 \mathrm{Aa}$ & $3,82 \mathrm{Ba}$ & $1,04 \mathrm{Ca}$ & $0,61 \mathrm{Da}$ \\
Bw2 (não-coeso) & $2,89 \mathrm{Ab}$ & $1,72 \mathrm{Bb}$ & $0,96 \mathrm{Cab}$ & $\mathrm{Cab}$ \\
\hline
\end{tabular}

Médias com letras maiúsculas iguais, na mesma linha, e letras minúsculas iguais, na mesma coluna, não diferem estatisticamente entre si pelo teste Tukey a $5 \%$.

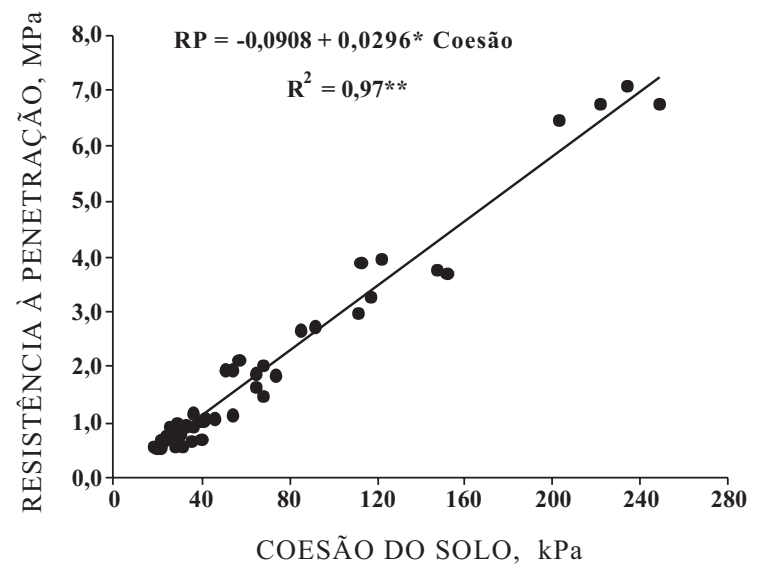

Figura 7. Relação entre resistência à penetração (RP, $\mathrm{MPa})$ e coesão (kPa) de um Latossolo Amarelo de São Miguel dos Campos, $\mathrm{Al}$, nos teores de água de $0,07,0,12,0,19$ e $0,24 \mathrm{~kg} \mathrm{~kg}^{-1}$.

de resistência à penetração em horizonte coeso de um Latossolo Amarelo de tabuleiro da Bahia, chegando a 12,8 MPa no solo com teor de água de $0,06 \mathrm{~kg} \mathrm{~kg}^{-1}$. De acordo com Canarache (1990), valores de resistência à penetração superiores a 2,5 MPa em solos argilosos são suficientes para restringir o crescimento e a penetração das raízes das plantas no solo.

\section{CONCLUSÕES}

1. A coesão e a resistência ao cisalhamento do solo aumentaram expressivamente com a redução do teor de água no horizonte BA (coeso).

2. O horizonte BA (coeso) apresentou os maiores valores de coesão e resistência ao cisalhamento do solo, refletindo o maior valor de densidade do solo e microporosidade em relação aos horizontes A e Bw2, bem como maiores teores de óxidos de Fe, $\mathrm{Si}$ e $\mathrm{Al}$ comparado ao horizonte $\mathrm{A}$.
3. A maior coesão do solo no horizonte BA refletiu em maior resistência do solo à penetração, em relação aos horizontes A e Bw2 (não-coesos), nos teores de água de 0,07 e $0,12 \mathrm{~kg} \mathrm{~kg}^{-1}$.

\section{LITERATURA CITADA}

ABRAHÃO, W.A.P.; COSTA, L.M.; MELLO, J.W.V. \& NEVES, J.C.L. Distribuição de freqüência de tamanho da fração areia e compacidade relativa de solos desenvolvidos de sedimentos do grupo geológico Barreiras. R. Bras. Ci. Solo, 22:1-9, 1998.

AL-SHAYEA, N.A. The combined effect of clay and moisture content on the behavior of remolded unsaturated soils. Eng. Geol., 62: 319-342, 2001.

AYERS, P.D. Moisture and density effects on soil shear strength parameters for coarse grained soils. Trans. Am. Soil Agric. Eng., 30:1282-1287, 1987.

BORGES, A.L. \& KIEHL, J.C. Cultivo de frutíferas perenes e de mandioca sobre as propriedades químicas de um Latossolo Amarelo álico de Cruz das Almas (BA). R. Bras. Ci. Solo, 21:341-345, 1997.

BOULET, R.; FRITSCH, E.; FILIZOLA, H.F.; ARAÚJO FILHO, J.C.; LEPRUN, J.C. \& ABRRETTO, F. Iron bands, fragipans and duripans in the northeastern plateaus of Brazil - properties and genesis. Canadian J. Soil Sci., 78:519-530, 1998.

CANARACHE, A. PENETR - a generalized semi-empirical model estimating soil resistance to penetration. Soil Till. Res., 16:51-70, 1990.

CHARTRES, C.J.; KIRBY, J.M. \& RAUPACH, M. Poorly ordered silica and aluminosilicates as temporary cementing agents in hardsetting soils. Soil Sci. Soc. Am. J., 54:1060-1067, 1990.

EMPRESA BRASILEIRA DE PESQUISA AGROPECUÁRIA EMBRAPA. Sistema brasileiro de classificação de solos. Brasília, 1999. 412p.

EMPRESA BRASILEIRA DE PESQUISA AGROPECUÁRIA EMBRAPA. Manual de métodos de análises de solo. Rio de Janeiro, 1997. 212p. 
FERREIRA, M.M.; FERNANDES, B. \& CURI, N. Mineralogia da fração argila e estrutura de latossolos da região Sudeste do Brasil. R. Bras. Ci. Solo, 23:507-514, 1999.

FILIZOLA, H.F.; LAMOTTE, M.; FRITSCH, E.; BOULET, R.; ARAÚJO FILHO, J.C.; SILVA, F.B.R. \& LEPRUN, J.C. Os fragipãs e duripãs das depressões dos tabuleiros costeiros do Nordeste brasileiro: Uma proposta de evolução. R. Bras. Ci. Solo, 25:947-963, 2001.

FRANZMEIER, D.P.; CHARTES, C.J. \& WOOD, J.T. Hardsetting soils in Southeast Australia: Landscape and profile processes. Soil Sci. Soc. Am. J., 60:1178-1187, 1996.

FREDLUND, D.G. \& RAHARDJO, H. Soil mechanics for unsaturated soils. New York, John Wiley, 1993. 517p.

GIAROLA, N.F.B.; SILVA, A.P.; TORMENA, C.; SOUZA, L.S. \& RIBEIRO, L.P. Similaridades entre o caráter coeso dos solos e o comportamento hardsetting. Estudo de caso. R. Bras. Ci. Solo, 25:239-247, 2001.

HILLEL, D. Fundamentals of soil physics. New York, Academic Press, 1980. 413p.

JACKSON, M.L. Soil chemical analysis: advanced course. 2.ed. Madison, Departament of Soil University Wisconsin, 1965. 991p.

JACOMINE, P.K.T. Distribuição geográfica, características e classificação dos solos coesos dos tabuleiros costeiros. In: REUNIÃO TÉCNICA SOBRE SOLOS COESOS DOS TABULEIROS COSTEIROS: "Pesquisa \& Desenvolvimento para os tabuleiros costeiros", Cruz das Almas. 1996. Anais. Cruz das Almas, Embrapa/CPATC/CNPMF/ IGUFAB, 1996. p.13-24.

JACOMINE, P.K.T.; CAVALCANTI, A.C.; PESSOA, S.C.P. \& SILVEIRA, C.O. Levantamento exploratório reconhecimento de solos de Estado de Alagoas. Recife, Embrapa/ Centro de Pesquisas Pedológicas, SUDENE-DRN, 1975. 531p. (Boletim Técnico, 35)

JONGERIUS, A. \& HEINTZBERGER, G. The preparation of mammoth-sized thin sections. Wageninger, Soil Survey Institute, 1963. p.3-37. (Soil Survey Paper, 1)

LAMBE, T.W. Soil testing for engineers. 2.ed. New York, John Wiley, 1951. 165p.

LAMBE, T.W. \& WHITMAN, R.V. Soil mechanics, SI version. New York, John Wiley, 1979. 553p.

LEBERT, M. \& HORN, T. A method to predict the mechanical strength of agricultural soils. Soil Till. Res., 19:275-286, 1991.

LIMA, H.V.; SILVA, A.P.; JACOMINE, P.T.K.; ROMERO, R.E. \& LIBARDI, P.L. Identificação e caracterização de solos coesos no Estado do Ceará. R. Bras. Ci. Solo, 28:467-476, 2004.

McKEAGUE, J.A. \& SPROUT, P.N. Cemented subsoils (Duric Horizons) in some soils of British Columbia. Canadian J. Soil Sci., 55:189-203, 1975.

McKYES, E.; NYAMUGAFATA, P. \& NYAMAPFENE, K.W. Characterization of cohesion, friction and sensitivity of two hardsetting soils from Zimbabwe. Soil Till. Res., 29:357-366, 1994.

MEHRA, O. P. \& JACKSON, M.L. Iron oxide removal from soils and clays by dithionite-citrate system buffered with sodium bicarbonate. In: NATIONAL CONFERENCE ON CLAYS AND CLAYS MINERALS, 7., Washington, 1958. Proceedings. New York, 1960. p.317-327.
MULLINS, C.E.; MaCLEOD, D.A.; NORTHCOTE, K.H.; TISDALL, J.M. \& YOUNG, I.M. Hardsetting soils: Behavior, occurrence and management. Adv. Soil Sci., 11:37-108, 1990.

ORTIGÃO, J.A.R. Introdução à mecânica dos solos dos estados críticos. 2.ed. Rio de Janeiro, Livros Técnicos e Científicos, 1995. 378p.

PINTO, C.S. Curso básico de mecânica dos solos. São Paulo, Oficina de Textos, 2000. 247p.

RIBEIRO, L.P. Evolução da cobertura pedológica dos tabuleiros costeiros e a gênese dos horizontes coesos. In: WORKSHOP COESÃO EM SOLOS DOS TABULEIROS COSTEIROS. Aracaju, 2001. Anais. Aracaju, Embrapa Tabuleiros Costeiros, 2001a. p.93-121.

RIBEIRO, M.R. Características morfológicas dos horizontes coesos dos solos de Tabuleiros Costeiros. In: WORKSHOP COESÃO EM SOLOS DOS TABULEIROS COSTEIROS. Aracaju. 2001. Anais. Aracaju, Embrapa Tabuleiros Costeiros, 2001b. p.161-168.

ROCHA, W.W.; DIAS JÚNIOR, M.S.; LIMA, J.M.; MIRANDA, E.E.V. \& SILVA, A.R. Resistência ao cisalhamento e grau de intemperismo de cinco solos na região de Lavras (MG). R. Bras. Ci. Solo, 26:297-303, 2002.

SILVA, A.J.N. Alterações físicas e químicas de um Argissolo Amarelo Coeso sob diferentes sistemas de manejo com cana-de-açúcar. Porto Alegre, Universidade Federal do Rio Grande do Sul, 2003. 120p. (Tese de Doutorado)

SILVA, A.J.N. \& CABEDA, M.S.V. Influência de diferentes sistemas de uso e manejo na coesão, resistência ao cisalhamento e óxidos de $\mathrm{Fe}, \mathrm{Si}$ e $\mathrm{Al}$ em solo de tabuleiro costeiro de Alagoas. R. Bras. Ci. Solo, 29:447-457, 2005.

SILVA, A.J.N. \& RIBEIRO, M.R. Caracterização de um Latossolo Amarelo sob cultivo contínuo de cana-de-açúcar no Estado de Alagoas: Propriedades químicas. R. Bras. Ci. Solo, 22:291-299, 1998.

SILVA, F.A.S.E. The ASSISTAT Software: statistical assistance. In: INTERNATIONAL CONFERENCE ON COMPUTERS IN AGRICULTURE, 6., Cancun, 1996. Anais. Cancun, American Society of Agricultural Engineers, 1996. p.294-298.

SILVA, M.S.L. Caracterização e gênese do adensamento subsuperficial em solos de tabuleiros do semi-árido do Nordeste do Brasil. Porto Alegre, Universidade Federal do Rio Grande do Sul, 2000. 126p. (Tese de Doutorado)

SILVA, R.B.; DIAS JÚNIOR, M.S.; SANTOS, F.L. \& FRANZ, C.A.B. Resistência ao cisalhamento de um Latossolo sob diferentes uso e manejo. R. Bras. Ci. Solo, 28:165-173, 2004.

SUPERIOR PERFORMING STATISTICAL SOFTWARE SPSS. SigmaStat for windows, version 2.03. Chicago, 1995.

UCHA, J.M. Processos de transformação Latossolo-Espodossolo sobre os sedimentos do Grupo Barreiras nos tabuleiros costeiros do litoral norte do Estado da Bahia. Salvador, Universidade Federal da Bahia, 2000. 196p. (Tese de Doutorado)

ZHANG, B.; ZHAO, Q.G.; HORN, R. \& BAUMGARTL T. Shear strength of surface soil as affected by soil bulk density and soil water content. Soil Till. Res., 59:97-106, 2001. 